\title{
Special Issue on JITEL 2013 Best Papers
}

\author{
Juan M. Lopez-Soler \\ Dept. of Signal Theory, Telematics, and Communications \\ University of Granada \\ Periodista Daniel Saucedo s/n, 18071, Granada (Spain) \\ Tel: +34958242303Ｅ-mail: juanma@ugr.es
}

Received: June 20, 2014

Accepted: June 30, 2014

Published: June 30, 2014

DOI: 10.5296/npa.v6i2.5962

\begin{abstract}
This editorial introduces the twelve best papers selected for this special issue from the XI Jornadas de Ingeniería TELemática (JITEL 2013) -XI Conference on Telematics Engineering-, held from 28 to 30 October 2013, in Granada (Spain).
\end{abstract}

Keywords: JITEL 2013, Telematics, Networking. 


\section{Introduction}

For this time, the city of Granada (Spain) is responsible for serving as host to the XI Jornadas de Ingeniería TELemática (JITEL 2013) -XI Conference on Telematics Engineering-, held from 28 to 30 October 2013.

JITEL conference, organized by the Spanish Telematics Association (ATEL -Asociación de Telemática-), constitutes a suitable forum for meeting, discussion and outreach to groups who teach and research on issues related to networks and services. JITEL aims at promoting the exchange of experiences and results among research groups working on telematics issues, as well as fostering future cooperation between them.

In this occasion, the Conference was inaugurated with the seminal keynote talk entitled Machine-to-Machine in Smart Cities: Vision, Technologies \& Applications by Prof. Mischa Dohler, King's College London, UK. Additionally, JITEL 2013 was organized in 11 sessions -ranging from green networking to traffic modeling and mobile networks issues, among many others- with 45 regular papers, and 2 sessions with 12 short papers. Alongside the mentioned sessions, the Conference also included two workshops focused on Security -with 8 papers- and Education Innovation in Networking and Telematics -including 12 papers-. For more details, please see the JITEL 2013 web site [1].

This Special Issue includes double blind extended versions of the 12 JITEL 2013 best papers. Given their high quality and number, the selected papers have been organized into two separate numbers of the journal. The rationale was to include miscellaneous front-line papers in the first number, while the cellular, sensor and wireless communications breakthrough papers will be published in the next Special Issue number. The two following Sub-sections provide a succinct explanation of the selected papers.

\subsection{Miscellaneous papers}

The first number of the Special Issue on JITEL 2013 Best Papers includes 7 papers. The first one [2] authored by A. Navas et al. proposes an automatic error detection system for REST services. It considers XML format based responses produced at multiple service innovations so that web services can be systematically tested as a black-box without knowing its full specification.

The paper of A. J. Estepa et al., from the University of Seville (Spain) [3] addresses the issue of selecting VoIP codecs by considering energy efficiency criteria. Particularly, they study the computational complexity impact on battery consumption of codecs, like AMR, G.729, G.723 and iLBC. Based on that, they propose an algorithm for dynamic codec selection on the client side. It considers the energy consumption besides of quality and bandwidth. The proposed algorithm is experimentally evaluated by measuring their battery life benefits.

J. L. Tornos et al. [4] propose a client-server eVoting System based on ring signatures. It uses the so called "linking tag" parameter that allows to identifying the different votes sent by 
a single voter during a voting process. In this way, the system knows if the vote belongs to a person who has already voted. Details on the proposed system design, implementation and evaluation are provided. Also related to security, and more precisely on privacy and user identity, the paper [5] authored by J. A. Estrada-Jiménez et al. describes and evaluates a way to measure the effectiveness of a query obfuscation method. The authors claim that for classifications attacks, the obfuscation mechanism was not successful enough for user privacy protection.

In the framework of the FP7 INTEGRIS Project European, the developed smart grid ICT research lines are detailed in [6], paper co-authored by J. M. Selga et al. from La Salle-University Ramon Llull, Barcelona. This paper -especially focused in the security domain- presents requirements, solutions and results developed and tested in the mentioned European project. It proposes a Layer 2 heterogeneous mesh network based on TRILL protocol, with supporting QoS mechanisms, plus a security subsystem, a data replication subsystem together with a context-aware intelligent subsystem which controls the whole system.

Last but not least, the performance of objective QoE metrics for adaptive streaming services is studied in paper [7] co-authored by A. Álvarez et al. In this work, the authors successfully perform extensive subjective experiments that show the user's preference towards adaptive streaming systems. Built upon a found strong correlation with subjective scores, the authors introduce objective metrics in the adaptive streaming algorithm, in such a way that the overall system performance is improved. Additionally, they claim that PSNR provides the worse results for reproducing human decisions.

\subsection{Cellular, sensor and wireless communications papers}

Five additional papers have also been selected to complete this Special Issue. They will be published in the next number of the Network Protocols and Algorithms journal.

The paper co-authored by R. Vilches et al. [8] proposes a modular architecture that uses the popular Raspberry $\mathrm{Pi}$ as a gateway to a sensor network. It is designed for creation of products and services to provide home automation functionalities and to improve the wellness of people, especially the elderly. The proposed system is capable of accommodating multiple services, from automation of blinds, lighting controls or security, to mechanisms for patient health monitoring.

The paper of R. Sanchez Iborra and M. D. Cano [9] focuses on video traffic sources for evaluating the performance of the following MANET routing protocols: Better Approach To Mobile Ad-hoc Networking (BATMAN), the Optimized Link State Routing (OLSR) and the Ad hoc On-Demand Distance Vector (AODV) IETF drafts. Particularly, the authors propose to adopt some cross-layer approaches that improve the multimedia traffic support in MANETs. 
The impact of secure mechanisms (VPN) on the costs (both technical and also economic) of cellular based M2M communications for smart grid is studied in the paper of El bachir El achhab et al. [10]. Particularly, in the framework of EU project ENERsip the paper addresses and compares IPSec (Internet Security Protocol) and TLS/SSL (Transport Layer Security/Secure Socket Layer).

In paper [11] D. Gomez Fernandez et al. from the University of Cantabria assess the behavior of Multipath TCP (MPTCP) for devices with multiple network interfaces. They evaluate three different routing algorithms (link, node and zone disjoint) that aim to discover the optimal route configuration of disjoint paths over a wireless mesh network, and claim that the aggregated MPTCP performance is significantly higher than the one achieved by the traditional single-path and single-flow TCP.

Finally the second number of the JITEL 2013 Special Issue includes the paper [12] co-authored by V. Casares-Giner et al., from Universidad Politécnica de Valencia. It considers the framed ALOHA protocol for a finite number of terminals. In this work, by means of Markovian tools, the authors derive the throughput and the delay under FIFO and LIFO queue disciplines, and discuss on the applicability of the studied protocol.

\section{Acknowledgement}

The successful JITEl 2013 Conference would not be possible without the ATEL support; and without the effective and unselfish work of the anonymous referees as well as the executive, the program and the local committees. To all of them, thanks.

\section{References}

[1] JITEL 2013 Web Site. Available at: http://dtstc.ugr.es/jitel2013/ (last accessed July 9, 2014)

[2] A. Navas, P. Capelastegui, F. Huertas, P. Alonso-Rodriguez, J. C. Dueñas: REST service testing based on inferred XML schema. Network Protocols and Algorithms, vol. 6 n. 2, June 2014. Pp. 6-20. http://dx.doi.org/10.5296/npa.v6i2.5360

[3] A. J. Estepa, R. Estepa, J. Vozmediano, P. Carrillo: Dynamic VoIP codec selection on Smartphone. Network Protocols and Algorithms, vol. 6 n. 2, June 2014. Pp. 21-37 http://dx.doi.org/10.5296/npa.v6i2.5370

[4] J. L. Tornos, J. L. Salazar, J. J. Piles, J. Saldana, L. Casadesus, J. Ruiz-Mas, J. Fernandez-Navajas: An eVoting System Based on Ring Signatures. Network Protocols and Algorithms, vol. 6 n. 2 June, 2014. Pp. 38-54. http://dx.doi.org/10.5296/npa.v6i2.5390

[5] J. A. Estrada-Jiménez, A. F. Rodríguez, J. Parra, J. Forné: Evaluation of a 
Query-Obfuscation Mechanism for the Privacy Protection of User Profiles. Network Protocols and Algorithms, vol. 6 n. 2, June 2014 . Pp. 55-92. http://dx.doi.org/10.5296/npa.v6i2.5395

[6] J. M. Selga, G. Corral, A. Zaballos, R. Martín de Pozuelo: Smart Grid ICT Research Lines out of the European Project INTEGRIS. Network Protocols and Algorithms, vol. 6 n. 2, June 2014. Pp. 93-122. http://dx.doi.org/10.5296/npa.v6i2.5439

[7] A. Álvarez, L. Pozueco, S. Cabrero, X. García Pañeda, R. García, D. Melendi, G. Díaz Orueta: Adaptive Streaming: A subjective catalog to assess the performance of objective QoE metrics. Network Protocols and Algorithms, vol. 6 n. 2, June 2014. Pp. 123-136. http://dx.doi.org/10.5296/npa.v6i2.5461

[8] R. Vilches, T. Oller, J. Alcober i Segura: Pervasive sensors network for wellness based-on Raspberry Pi. Network Protocols and Algorithms, vol. 6 n. 3, September 2014. Pp. 1-17. http://dx.doi.org/10.5296/npa.v6i3.5424

[9] R. Sanchez Iborra, M.D. Cano: An approach to a cross layer-based QoE improvement for MANET routing protocols. Network Protocols and Algorithms, vol. 6 n. 3, September 2014. Pp. 18-34. http://dx.doi.org/10.5296/npa.v6i3.5827

[10] El bachir El achhab, G. López , J. I. Moreno: On the Impact of Virtual Private Network Technologies on the Operational Costs of Cellular Machine-to-Machine Communications Platforms for Smart Grids. Network Protocols and Algorithms, vol. 6 n. 3, September 2014. Pp. 35-55. http://dx.doi.org/10.5296/npa.v6i3.5374

[11] David Gómez, Pablo Garrido, Carlos Rabadán and Ramón Agüero and Luis Muñoz, TCP Performance Enhancement over Wireless Mesh Networks by means of the Combination of Multi-RAT Devices and the MPTCP Protocol. Network Protocols and Algorithms, vol. $6 \mathrm{n}$. 3, September 2014. Pp. 56-81. http://dx.doi.org/10.5296/npa.v6i3.5387

[12] V. Casares-Giner, V. Sempere-Payá, D. Todolí-Ferrandis: Framed ALOHA Protocol with FIFO-Blocking and LIFO-Push out Discipline. Network Protocols and Algorithms, vol. 6 n. 3 , September 2014. Pp. 82-102. http://dx.doi.org/10.5296/npa.v6i3.5557

\section{Copyright Disclaimer}

Copyright reserved by the author(s).

This article is an open-access article distributed under the terms and conditions of the Creative Commons Attribution license (http://creativecommons.org/licenses/by/3.0/). 